\title{
Identity Formation and Reformation in First and Second Career Psychiatric Residents
}

\author{
Steven J. Kingsbury, M.D., Ph.D. \\ Harvard University, Boston, Massachusetts
}

Follow this and additional works at: https://jdc.jefferson.edu/jeffjpsychiatry

Part of the Psychiatry Commons

Let us know how access to this document benefits you

\section{Recommended Citation}

Kingsbury, M.D., Ph.D., Steven J. (1989) "Identity Formation and Reformation in First and Second Career Psychiatric Residents," Jefferson Journal of Psychiatry. Vol. 7 : Iss. 2 , Article 11.

DOI: https://doi.org/10.29046/JJP.007.2.009

Available at: https://jdc.jefferson.edu/jeffjpsychiatry/vol7/iss2/11

This Article is brought to you for free and open access by the Jefferson Digital Commons. The Jefferson Digital Commons is a service of Thomas Jefferson University's Center for Teaching and Learning (CTL). The Commons is a showcase for Jefferson books and journals, peer-reviewed scholarly publications, unique historical collections from the University archives, and teaching tools. The Jefferson Digital Commons allows researchers and interested readers anywhere in the world to learn about and keep up to date with Jefferson scholarship. This article has been accepted for inclusion in Jefferson Journal of Psychiatry by an authorized administrator of the Jefferson Digital Commons. For more information, please contact: JeffersonDigitalCommons@jefferson.edu. 


\title{
Identity Formation and Reformation in First and Second Career Psychiatric Residents
}

\author{
Steven J. Kingsbury, M.D., Ph.D.
}

Although all residents seek to acquire competence, those entering psychiatry as a first career appear to use different strategies for the early protection of self esteem than do those entering psychiatry as a second career. These differences and their ramifications for the resident and the residency are discussed.

Differences appear in the formation of a professional identity as a psychiatrist when that career is the second career as opposed to the formation of that identity when the career is the first. For most older psychiatric residents, a first career typically precedes the entrance into psychiatry. In my case, I was a professor of clinical psychology with a part-time private practice which I maintained through medical school. Similarly several other older residents I knew worked in their previous professions such as pharmacy or nursing while in medical school, thereby blocking their total immersion in medicine. However other older residents did not work, but the differences to be discussed nevertheless seem to have occurred. It should be noted that the ordering of these differences are based upon my impressions, experiences, and discussions with other residents.

In any professional training program, there is the basic disparity between the trainee and the competent others who are training the initiate, who demonstrate the skills, conduct, and assurance of the group the trainee wishes to join. To use social comparison theory $(1,2)$, the trainers serve as the reference group with which the trainee identifies. However the trainee realizes his or her lack of membership in the reference group. Daily, the trainee sees evidence of the lack of professional identity, including a lack of knowledge and a clumsiness in one's approach to the problems encountered.

Especially in the approach to problems such as diagnosis or the treatment choices the trainee must make, the trainee is confronted by the disparity between the skilled professional and himself. This disparity leads to a state of discomfort which the trainee will seek to reduce. Whether first or second career, the long term manner of reducing discomfort is the same-to become trained and competent. However, this process takes years, and short term, partial solutions are used to reduce discomfort especially during the early part of training. It appears that the short term, early accomodations are different for those entering their first versus their second careers.

For those entering their first career, there are no set patterns of competent 
professional behavior. Rather one borrows wholesale, acting like junior copies of admired professors. For example, I tried to interview like certain professors in graduate school, even lifting phrases and mannerisms. Sometimes this helped a little, sometimes less and I would shift to imitating someone else, trying on different personas. For a while I was a Sullivanian, a behaviorist, a cognitive therapist, and others, but gradually I began to fit these incorporations into a beginning semblance of a professional identity of my own, which I then proceeded to modify in the course of further training. Similarly I note first career graduate students and residents aping the phrases, gestures, and judgements of senior staff. This pretend or borrowed competence is a salve for insecurity (cf., 3).

Those entering a second career already know how to perform as competent professionals, though not as a professional psychiatrist. Therefore these residents lean on the comfortable structures they know, modifying them with helpful knowledge and algorithms they find useful. For me, this meant leaning on my skills in psychdiagnosis and psychotherapy, demonstrating competence in interviewing, for example, while I scrambled to become competent in psychopharmacology or the organic differentials for different presentations. Similarly, an internist I know staked his territory in the careful workup of organic differentials while scrambling to develop psychological competence. Thus the trainee in his second career uses the smokescreen of previous competence, while true competence and identity develop.

Although good professors are respected by those entering their second career, they are viewed differently and more critically than by those in their first career, since the professors often lack some specific competencies as viewed by those with related but separate competence. Still, specific skills, such as where to place ECT electrodes or knowledge such as the workup of neuroleptic malignant syndrome are eagerly learned, despite realizing that the same professor is truely ignorant about setting up an adequate research design or when to use projective tests. Professors are therefore seen as more human, equals but with different and valued skills rather than being idealized (or unfairly disparaged). This difference is more evident early in the residency.

These different manners of protecting self esteem may lead to staff having different reactions to first and second career residents. The first career resident, using imitation, is seen as likable but perhaps less creative and competent. The second career resident, leaning on previous competencies, may be seen as more competent but somewhat resistant to training since the acquiring of competence in the new career is more hidden.

Prior competencies can be a two edged sword that creates both positive and negative reactions from both attendings and fellow residents. For example, a former internist included porphyria as a differential diagnosis and confirmed it while simultaneously making elementary errors in the management of a borderline patient. Similarly, while successfully helping a patient with Raynaud's 
syndrome through the use of hypnosis, I also frequently undermedicated patients early in my training.

Although fellow residents would, at times, seek out the expertise of residents with prior expertise, they also could resent such behavior from attendings. As an example, a fellow resident once expressed annoyance when I was told to take a particularly difficult patient out of turn. The resident felt this was a slight on her ability, despite the attending actually respecting her capabilities.

Although these generalizations are broad and perhaps too dichotomous, I believe them to be accurate. Similarly, although my sample is small, other generalizations about the effects of these differences on the training experience of each may be made.

To start glibly, because of the wholesale identification with others, the first career resident often feels himself or herself to be a psychiatrist before he or she is, while the second career resident, more secure in previous competencies than newly acquired skills, identifies as a psychiatrist later than need be. To be a psychiatrist unequivocally denies the previous work and one's other competencies, which would create uncomfortable cognitive dissonance (4).

So I was a psychologist in my first year of graduate school, although in retrospect not as competent as I thought. Now, a month away from board eligibility I typically define myself as a "shrink," and often feel most like a psychologist when I am with psychiatrists, and often most like a psychiatrist when I am with psychologists, since interactions with each group highlights differences beyond the commonalities (5).

I also believe attending psychiatrists react to each group differently, creating different expectations which further add to the dissimilarities between first and second career residents. To continue down the path of overgeneralization, the first career resident flatters the attending by trying to emulate his or her role models. Younger and typically more energetic and eager, the first career resident often becomes an apprentice to a mentor, developing similar clinical and research interests.

If the first career resident is more flattering, the second career resident is more interesting. Attendings appear more challenged and desirous of using the second career resident for their own intellectual stimulation and growth while they also teach the resident. Often the second career resident has interests formulated even before entering the residency. The joining of pre-existing research programs is based on overlapping interest which led to that choice of residency or to some skill leading to the invitation to join in. As examples, I have joined research programs at my residency in part because of prior skills in experimental design and statistical analysis. Similarly, it is not infrequent that attendings discuss their cases, leading often to a collegial rather than a mentoring relationship.

Several other differences between first and second career residents affecting their professional identity may be briefly mentioned. First, the older second career resident is more often bound to an area and settled into a community. 
Therefore they are less dependent upon the residency and fellow residents to fill their social needs, leading to less talk of work in social situations since it is not as much a shared experience. This may lead to older residents being seen as aloof or as just simply slightly separate from the residency group.

Secondly, residencies are typically designed for the first career resident with exposure to all aspects of the discipline. The broad base is coupled with the service requirements of the residency which may lead to a lack of flexibility in meeting the needs or acknowledging the competencies of the second career resident. This inflexibility coupled with some discomfort engendered by a different way of training (5) may lead to some dissatisfaction with the program for the second career resident. For example, people trained as graduate students through seminars and library searches may at first be uncomfortable with having experiences to be integrated with didactic material occurring later.

The first careers of second career residents may be diverse, and the different accomodations necessary can be difficult for a residency program. As an example, several residents with Ph.D.'s who sought to reinvolve themselves in research during their residency (including one with a research grant) were restricted from research by the service requirements. In at least one case, the chairman of a department and the residency director specifically told a resident to wait until graduation or fellowship before pursuing further research due to the primacy of the service demands.

In summary, the second career resident faces problems and rewards which are different from those faced by first career residents. Understanding the differences will maximize the experience for all, and hopefully lead to increased diversity and richness in psychiatry.

\section{REFERENCES}

1. Festinger L: A theory of social comparison processes. Human Relations 7:117-140, 1954

2. Pettigrew TF: Social evaluation theory: Convergences and applications, in Nebraska Symposium on Motivation, 1967. Edited by Levine D, Lincoln, Nebraska, University of Nebraska Press, 1967

3. Light D: Becoming Psychiatrists: The Professional Transformation of Self. New York, Norton, 1980

4. Aronson E, Mills J: The effect of severity of initiation on liking for a group. J Abnormal and Social Psychology 59:177-181, 1959

5. Kingsbury SJ: Cognitive differences between clinical psychologists and psychiatrists. Am Psychologist 42:152-156, 1987 